\title{
Efeito do Substrato na Morfologia de Conídios de Bipolaris sorokiniana e da Densidade de Inóculo na Intensidade da Mancha Marrom em Cevada*
}

\author{
Javier Toledo Barba ${ }^{1}$, Erlei M. Reis ${ }^{2} \&$ Carlos A. Forcelini ${ }^{2}$ \\ ${ }^{1}$ Centro de Investigación Agrícola Tropical (CIAT), Santa Cruz, Bolívia; ${ }^{2}$ Faculdade de Agronomia e Medicina Veterinária, \\ Mestrado em Agronomia, Área de Concentração Fitopatologia, Universidade de Passo Fundo, Cx. Postal 611, CEP 99001-970, \\ Passo Fundo, RS
}

(Aceito para publicação em 20/11/2002)

Autor para correspondência: Erlei Melo Reis

TOLEDO, J., REIS, E.M. \& FORCELINI, C.A. Efeito do substrato na morfologia de conídios de Bipolaris sorokiniana e da densidade de inóculo na intensidade da mancha marrom em cevada. Fitopatologia Brasileira 29:005-010. 2004.

\section{RESUMO}

O fungo Bipolaris sorokiniana causa a mancha marrom da cevada (Hordeum vulgare), doença foliar amplamente distribuída no mundo. A sua identificação ou diferenciação de outras espécies baseia-se principalmente na variação morfológica dos esporos. Porém, muitos fatores podem alterar o tamanho e a septação dos conídios dentro da espécie. O presente trabalho objetivou estudar o efeito de diferentes substratos no tamanho, septação e morfologia de conídios de B. sorokiniana, assim como o efeito da densidade de inóculo na intensidade da mancha marrom em plantas de cevada. Os substratos constaram de seis meios de cultura, de sementes e folhas verdes de cevada, trigo (Triticum aestivum), centeio (Secale cereale) e triticale (Triticum secalotricum). O tipo de substrato afetou significativamente o comprimento, a largura e o número de pseudoseptos de B. sorokiniana. Os esporos desenvolvidos em meios de cultura $(68,2$ $\times 21,9 \mu \mathrm{m} ; 5,7$ pseudoseptos $)$ e em sementes $(78,3 \times 20,4 \mu \mathrm{m}$ e 7,2 pseudoseptos) foram mais curtos, mais largos e com menor número de pseudoseptos, além de serem mais escuros e retos, em relação aos recuperados de tecidos verdes $(92,9 \times 18,2 \mu \mathrm{m}$ e 7,7 pseudoseptos). $\mathrm{O}$ efeito da densidade de inóculo foi testado através da aplicação de suspensões de esporos contendo $2,5 \times 10^{3}, 5 \times 10^{3}$, $10 \times 10^{3}, 15 \times 10^{3}$ e $20 \times 10^{3}$ conídios $/ \mathrm{ml}$ a plantas de cevada do cultivar BR-2. A relação com a intensidade da mancha marrom seguiu uma tendência polinomial quadrática, na qual os pontos máximos corresponderam a 183 manchas/folha (16.500 esporos/ml) e 79\% de severidade (14.000 esporos/ml). Estimou-se que 50 a 90 esporos foram necessários para produzir uma lesão.

Palavras-chave adicionais: Hordeum vulgare, concentração de esporos, nutrição.

\section{ABSTRACT}

Effect of growing substrates on the morphology of Bipolaris sorokiniana conidia and the relationship of inoculum density to disease intensity for brown spot of barley

The fungus Bipolaris sorokiniana causes brown spot, a barley (Hordeum vulgare) disease, worldwide. Identification of the fungus is based mainly on the morphology of its conidia, whose size and septation may be altered by many factors. This research studies the effect of growing substrates on the size, septation, and morphology of conidia, as well as the relationship of inoculum density to disease intensity. The various substrates included six culture media, seeds, and fresh leaves of barley, wheat (Triticum aestivum), rye (Secale cereale), and triticale (Triticum secalotricum). Conidia formed in culture media $(68,2 \times 21,9 \mu \mathrm{m} ; 5,7$ pseudosepta) and on seeds $(78,3 \times 20,4$ $\mu \mathrm{m} ; 7,2$ pseudosepta) were shorter, wider, and with less septa than those from leaf lesions $(92,9 \times 18,2 \mu \mathrm{m} ; 7,7$ pseudosepta). The effect of the inoculum density (ID) on disease intensity (DI) was tested by applying spore suspensions $\left(2.5 \times 10^{3}, 5.0 \times 10^{3}, 10.0 \times 10^{3}, 15.0 \times 10^{3}\right.$, and $20.0 \times 10^{3}$ conidia $/ \mathrm{ml}$ ) to plants of the barley cultivar BR-2. The ID/DI relationship was represented by a quadratic model equation, in which the maximum values of 183 lesion/leaf and $79 \%$ disease severity were obtained with 16.500 and 14.000 conidia/ml, respectively. The number of conidia required for one leaf lesion was estimated in 50 to 90 .

\section{INTRODUÇÃO}

A mancha marrom, mancha foliar ou helmintosporiose da cevada (Hordeum vulgare L.), causada pelo fungo Bipolaris sorokiniana (Sacc.) Shoem. [sinônimos: Helminthosporium sativum Pammel, King \& Bakke; Drechslera sorokiniana

\footnotetext{
*Parte da Dissertação de Mestrado do primeiro autor. Universidade de
} Passo Fundo (2001).
(Sacc.) Subram. \& Jain, H. californicum Mackie \& Paxton e $H$. sorokinianum Saccardo in Sorokin], anamorfo de Cochliobolus sativus (Ito \& Kurib.) Drechs. ex Dastur, é uma doença amplamente difundida no mundo, sendo encontrada em todas as regiões onde o cereal é cultivado (Sivanesan, 1987; Steffenson, 1997).

Segundo Luttrell (1955), uma das causas pelas quais o fungo $B$. sorokiniana apresentou diferentes denominações 
ou sinônimos durante os primeiros 25 anos após a sua primeira descrição, em 1890, foi, principalmente, as variações morfológicas dos conídios, originados de diferentes regiões geográficas e substratos. Estudos revelaram que os conídios de $B$. sorokiniana apresentam variações morfológicas no tamanho e na forma quando são produzidos em diferentes substratos, observações também relatadas por Ellis (1971) e Sivanesan (1987). Em geral, o fungo caracteriza-se por apresentar grande variabilidade, tanto morfológica quanto fisiológica (Tinline, 1988; Matsumura apud Oliveira et al., 1998). Nesse sentido, Ruppel (1974) indica que a identificação ou diferenciação de espécies da maioria dos fungos baseia-se sobretudo na variação do tamanho das estruturas que eles produzem. Porém, muitos fatores podem alterar o tamanho dos conídios dentro da mesma espécie, dos quais os mais comuns são o meio de cultura sobre o qual o fungo é cultivado, a idade da cultura e a temperatura.

Durante o processo de identificação de uma doença, a inoculação artificial é efetuada como parte dos postulados de Koch. Segundo a FAO (1985), a inoculação pode ser utilizada em diversos estudos fitopatológicos, dependendo do objetivo do trabalho. Em alguns casos, é necessário determinar a densidade, ou concentração ideal, e o potencial do inóculo (Baker apud FAO, 1985), isso com a finalidade de conseguir resultados satisfatórios e reproduzíveis (padronização), assim como para conhecer aspectos biológicos do patógeno e epidemiológicos da doença (Fernandes et al., 1991).

Nesse sentido, o presente trabalho objetivou estudar o efeito de diferentes substratos no tamanho e morfologia de conídios do fungo B. sorokiniana, bem como o efeito da densidade de inóculo na intensidade da mancha marrom em plântulas de cevada.

\section{MATERIALEMÉTODOS}

\section{Substratos vs. morfologia de conídios}

Substratos. Conídios de $B$. sorokiniana foram obtidos de três diferentes tipos de substratos: a) meios de cultura e/ou substrato: batata-dextrosa-ágar (BDA), V-8-ágar (V-8), ágarágua (AA), extrato de tomate-ágar (ETA), papel-filtro (PF) e meio seletivo de Reis (MSR); b) sementes: cevada (SCv), trigo (Triticum aestivum L.) (STg), centeio (Secale cereale L.) (SCt) e triticale (Triticum secalotricum Meister) (STt), e c) folhas: cevada (FCv), trigo (FTg), centeio (FCt) e triticale (FTt). Para o desenvolvimento do fungo, as sementes foram acondicionadas em placas de petri com três discos de papel-filtro esterilizados, umedecidos (3,5 ml de água destilada esterilizada/disco), utilizando-se dez sementes com sintomas de ponta preta, incubadas por um período de sete dias. No caso dos conídios provenientes de tecidos verdes, folhas com sintomas avançados (lesões velhas com esporulação aparente natural) de mancha marrom ou helmintosporiose foram coletadas diretamente no campo.

Mensuração dos conídios. Foi realizada a partir de suspensão de esporos do fungo em água destilada esterilizada $(2 \mathrm{ml})$, da qual se pipetou uma amostra de $30 \mu$ l sobre lâmina de microscopia. A medição foi feita em microscópio ótico, com micrômetro acoplado, na magnitude de $40 \times$.

Características avaliadas e análise estatística. Foram determinados o comprimento, a largura (região mais larga do conídio) e o número de pseudoseptos de 25 conídios, aleatoriamente, em cada uma das quatro repetições (total de 100 conídios). Posteriormente, o comprimento e a largura foram transformados em função da equação: $y=2,5(x)$, para se obter os valores reais das características medidas. O delineamento experimental foi inteiramente casualizado. As variáveis comprimento, largura e número de pseudoseptos foram submetidas à análise de variância $(\mathrm{P}<0,05)$, comparando-se as médias pelo teste de $\mathrm{Scott} \& \mathrm{Knott}(5 \%)$ e contrastes ortogonais $(5 \%)$. Previamente à análise de variância, os valores foram submetidos ao teste de Kolmogorov \& Smirnov para testar a sua normalidade.

\section{Densidade de inóculo vs. intensidade de doença}

Cultivo das plantas. Sementes de cevada do cultivar BR 2 foram distribuídas em 20 vasos de plástico (cinco sementes por vaso), correspondentes a quatro repetições por densidade de inóculo, com capacidade de 1 a $2 \mathrm{~kg}$ de substrato, contendo solo de horta peneirado e $\mathrm{pH}$ 6. O solo foi umedecido com água + adubo para fertirrigação (Niphokam $1 \mathrm{ml} / 1$ de água). A semeadura foi feita a $2 \mathrm{~cm}$ de profundidade. Cinco dias após a emergência, as plântulas foram raleadas, deixando-se cinco por vaso. Os vasos permaneceram em casa de vegetação por 15 dias, sendo, então, transferidos para uma câmara climatizada $\left(20 \pm 1^{\circ} \mathrm{C}\right.$ e fotoperíodo de $12 \mathrm{~h}$ ) por mais 12 dias. No estádio de duas a três folhas verdadeiras (além da plúmula), as plantas foram inoculadas com B. sorokiniana.

Obtenção do inóculo. O inóculo foi obtido a partir de colônias monospóricas com 14 dias, desenvolvidas em meio de batatasacarose-ágar + antibiótico (BSA + A). O fungo $B$. sorokiniana foi isolado de sementes de cevada (cultivar BR-2) naturalmente infetadas, as quais foram desinfestadas em solução aquosa de hipoclorito de sódio a $0,5 \%$ durante 5 min e, depois, lavadas com água destilada esterilizada. Dez sementes foram dispostas em cada placa de petri contendo meio seletivo de Reis (Reis, 1983), em um total de cinco placas. A seguir, as placas foram incubadas em sala de crescimento com fotoperíodo de $12 \mathrm{~h}$ e temperatura de $25 \pm 2{ }^{\circ} \mathrm{C}$, durante sete dias. Após a incubação, as sementes foram examinadas sob microscópio estereoscópico (magnitude de $50 \mathrm{X}$ ) quanto à formação de conídios de $B$. sorokiniana. Com a ajuda de uma agulha histológica flambada, micélio e conídios (na superfície da cariopse) foram transferidos para uma placa de petri contendo meio ágar-água. Conídios individuais foram, então, transferidos para o meio de cultura definitivo (BSA), sendo um esporo por placa e cinco repetições. A incubação ocorreu por dez dias, nas mesmas condições descritas anteriormente.

Após a incubação, procedeu-se à escolha de uma das colônias desenvolvidas (com características representativas do fungo), com a qual se trabalhou no transcurso do expe- 
Efeito do substrato na morfologia de conídios de Bipolaris sorokiniana...

rimento. Decorridos dez dias, pequenas porções da colônia foram transferidas para tubos de ensaio contendo BSA, durante sete dias e armazenadas em refrigerador $\left(10 \pm 1{ }^{\circ} \mathrm{C}\right)$. Outra parte da cultura pura foi colocada em placas de petri com BSA e incubada nas mesmas condições durante sete dias para o aumento de inóculo.

Preparo da suspensão do inóculo: A partir das culturas puras produzidas, preparou-se uma suspensão de esporos em água esterilizada + tween 20 ( 2 gotas/1), cuja densidade de inóculo foi determinada contando-se o número de esporos contidos em uma gota de volume conhecido por varredura ao microscópio (lamínula de $24 \times 32 \mathrm{~mm}$ ). A concentração final foi ajustada para $2 \times 10^{4}$ conídios $/ \mathrm{ml}$. A partir dessa concentração, e por diluição, obtiveram-se concentrações de $1,5 \times 10^{4}, 1 \times$ $10^{4}, 5 \times 10^{3}$ e $2,5 \times 10^{3}$. As diferentes suspensões foram armazenadas por algumas $\mathrm{h}(2-8 \mathrm{~h})$ em refrigerador $\left(10 \pm 1^{\circ} \mathrm{C}\right)$, previamente à inoculação, para evitar a germinação dos esporos.

Inoculação e incubação das plantas. Plantas com 27 dias de idade foram inoculadas com as cinco concentrações de inóculo (descritas no parágrafo anterior). Para isso, preparou-se um volume de $300 \mathrm{ml}$ de suspensão de conídios em água para cada uma das concentrações. $O$ volume final utilizado variou de 200 a $230 \mathrm{ml}$ por tratamento (cinco repetições ou vasos com quatro a cinco plantas), sendo aplicado através de um atomizador manual comum (plástico). Plantas de cinco vasos foram inoculadas com água destilada esterilizada como testemunha. A inoculação foi iniciada com a testemunha e, na seqüência, da menor para a maior concentração $\left(2 \times 10^{4}\right)$.

As plantas inoculadas foram protegidas com câmaras plásticas, previamente atomizadas com água nas suas paredes internas para assegurar alta percentagem de umidade relativa (>95\%) e manter o molhamento foliar das plantas. O solo dos vasos foi umedecido pela adição de $500 \mathrm{ml}$ de água nas bandejas. As plantas foram mantidas nessas condições por 48 $\mathrm{h}$, à temperatura de $25 \pm 1^{\circ} \mathrm{C}$. Após a remoção da proteção, as plantas foram mantidas em câmara climatizada até a manifestação dos sintomas da doença.

Características avaliadas e análise estatística. Quando do aparecimento dos sintomas e antes das manchas coalescerem (lesões de 0,2 a $0,5 \mathrm{~mm}$ ), procedeu-se à contagem do número de lesões por folha (quatro dias após da inoculação) e à avaliação da severidade por folha ou percentagem da área foliar afetada (\% AFA) (sete dias após da inoculação). As avaliações foram feitas na primeira e segunda folhas desenvolvidas após a plúmula. $\mathrm{O}$ delineamento experimental empregado foi inteiramente casualizado. Os valores obtidos foram submetidos à análise de distribuição normal, análise de variância e à regressão polinomial.

\section{RESULTADOS E DISCUSSÃO}

\section{Substratos vs. morfologia de conídios}

As características conidiais de B. sorokiniana, relativas ao comprimento, largura e número de pseudoseptos, além de outros aspectos importantes não mensuráveis, como a forma e a coloração dos conídios, foram afetadas significativamente pelos diferentes substratos utilizados.

Pode-se observar (Tabela 1) que, entre os meios de cultura utilizados, os conídios desenvolvidos no MSR apresentaram os maiores valores médios de comprimento (76,6 $\mu \mathrm{m})$, enquanto que os esporos mais largos foram encontrados nos meios BDA, PF, AA e MSR (22,15 a 22,78 $\mu \mathrm{m})$, característica que evidenciou a menor variabilidade entre os meios de cultura.

Em relação ao número de pseudoseptos, o meio ETA evidenciou o valor mais alto $(6,8)$. Em relação aos conídios desenvolvidos em sementes, os provenientes de SCt e STg foram os mais compridos (82,63 e $81,3 \mu \mathrm{m})$, ao passo que os desenvolvidos em SCv e SCt foram os mais largos (21,65 e $20,83 \mu \mathrm{m}$, respectivamente). O maior número de pseudoseptos foi encontrado nos conídios recuperados de STg $(7,7)$.

Quanto aos conídios desenvolvidos em folhas verdes, as diferenças estatísticas são menores, principalmente quando se referem a comprimento $(92,78-95,73 \mu \mathrm{m})$, no qual apenas os conídios provenientes de FTt apresentaram o menor valor médio $(88,53 \mu \mathrm{m})$, estatisticamente diferente dos demais. Os conídios mais largos foram os desenvolvidos em FCt (19,48 $\mu \mathrm{m})$, sendo que os provenientes das folhas dos outros cereais foram mais uniformes. O maior número de pseudoseptos ocorreu nos conídios recuperados de $\mathrm{FCt}(8,25)$ e FCv $(8,03)$.

$\mathrm{Na}$ Tabela 2, apresentam-se os valores extremos de comprimento, largura e número de pseudoseptos encontrados em conídios de $B$. sorokiniana recuperados de diferentes substratos. É possível observar que os valores máximos oscilaram entre 88 e $128 \mu \mathrm{m}$ de comprimento, 21 a $33 \mu \mathrm{m}$ de largura e um número de oito a 12 pseudoseptos; os valores mínimos tiveram uma variação de 25 a $71 \mu \mathrm{m}$ no comprimento, 14 a $18 \mu \mathrm{m}$ na largura e um a cinco pseudoseptos. Por outro lado, é possível notar que os conídios desenvolvidos sobre folhas verdes, independentemente da espécie de cereal de onde foram recuperados, apresentaram os maiores valores extremos de comprimento (máximo e mínimo), sendo superiores aos demais.

Em função da diferença acentuada no comprimento dos conídios produzidos em folhas verdes, realizaram-se comparações através de contrastes ortogonais com a finalidade de estabelecer diferenças estatísticas gerais nas características avaliadas entre os esporos desenvolvidos nos três tipos de substratos (Tabela 2). O resultado da análise de contrastes ortogonais dos valores médios, evidenciou uma diferença significativa em tamanho (comprimento e largura) e número de pseudoseptos entre os conídios desenvolvidos em meios de cultura, sementes e tecidos verdes (folhas).

Em geral, é possível deduzir que os esporos desenvolvidos em folhas verdes foram estatisticamente os mais compridos e, ao mesmo tempo, os mais estreitos $(92,9 \times 18,2$ $\mu \mathrm{m})$, situação oposta à que ocorreu com os conídios desenvolvidos em meios de cultura $(68,2 \times 21,9 \mu \mathrm{m})$. Por outro lado, os esporos desenvolvidos sobre sementes apresentaram dimensões de $78,3 \times 20,4 \mu \mathrm{m}$. 
J.T. Barba et al.

TABELA 1 - Comprimento, largura e número de pseudoseptos de conídios de Bipolaris sorokiniana desenvolvidos em diferentes substratos

\begin{tabular}{|c|c|c|c|}
\hline Substrato $^{1}$ & $\begin{array}{c}\text { Comprimento } \\
(\mu \mathrm{m})\end{array}$ & $\begin{array}{c}\text { Largura } \\
(\mu \mathrm{m})\end{array}$ & $\begin{array}{c}\text { Número de } \\
\text { pseudoseptos }\end{array}$ \\
\hline \multicolumn{4}{|c|}{ Meios de cultura } \\
\hline $\mathrm{BDA}^{2}$ & $65,28 \mathbf{f}^{3}$ & $22,78 \mathbf{a}^{3}$ & $4,83 \mathbf{d}^{3}$ \\
\hline $\mathrm{V}-8^{2}$ & $59,98 \mathbf{g}$ & $21,03 \mathbf{b}$ & $5,30 \mathbf{d}$ \\
\hline $\mathrm{AA}^{2}$ & $65,93 \mathbf{f}$ & $22,33 \mathbf{a}$ & $5,83 \mathbf{c}$ \\
\hline ETA $^{2}$ & $70,10 \mathbf{e}$ & $20,73 \mathbf{b}$ & $6,80 \mathbf{b}$ \\
\hline $\mathrm{PF}$ & $71,08 \mathbf{e}$ & $22,53 \mathbf{a}$ & $5,93 \mathbf{c}$ \\
\hline MSR & $76,60 \mathbf{d}$ & $22,15 \mathbf{a}$ & $5,73 \mathbf{c}$ \\
\hline \multicolumn{4}{|l|}{ Sementes } \\
\hline $\mathrm{SCV}$ & $73,95 \mathbf{d}$ & $21,65 \mathbf{b}$ & $6,40 \mathbf{c}$ \\
\hline STg & $81,30 \mathbf{c}$ & $19,33 \mathbf{c}$ & $7,75 \mathbf{a}$ \\
\hline $\mathrm{SCt}$ & $82,63 \mathbf{c}$ & $20,83 \mathbf{b}$ & $7,40 \mathbf{b}$ \\
\hline STt & $75,65 \mathrm{~d}$ & $19,85 \mathbf{c}$ & $7,25 \mathbf{b}$ \\
\hline \multicolumn{4}{|l|}{ Folhas } \\
\hline $\mathrm{FCv}$ & $94,70 \mathbf{a}$ & $17,75 \mathbf{d}$ & $8,03 \mathbf{a}$ \\
\hline FTg & $92,78 \mathbf{a}$ & $17,70 \mathbf{d}$ & $7,18 \mathbf{b}$ \\
\hline $\mathrm{FCt}$ & $95,73 \mathbf{a}$ & $19,48 \mathbf{c}$ & $8,25 \mathbf{a}$ \\
\hline FTt & $88,53 \mathbf{b}$ & $18,05 \mathbf{d}$ & $7,45 \mathbf{b}$ \\
\hline Média & 78,16 & 20,44 & 6,72 \\
\hline C.V. (\%) & 4,70 & 3,27 & 6,15 \\
\hline D.M.S. (5\%) & 5,25 & 0,95 & 0,59 \\
\hline
\end{tabular}

(1)Meios de cultura: batata-dextrosa-ágar (BDA), V-8-ágar (V-8), ágarágua (AA), extrato de tomate-ágar (ETA), papel-filtro (PF) e meio seletivo de Reis (MSR); Sementes: cevada (SCv), trigo (STg), centeio (SCt) e triticale (STt); Folhas: cevada (FCv), trigo (FTg), centeio (FCt) e triticale $(\mathrm{FTt})$.

(2)Meios de cultura $+0,2 \mathrm{~g}$ de estreptomicina por litro de água.

(3)Médias seguidas por letras distintas na vertical diferem entre si pelo teste de Scott \& Knott (5\%).

No relacionamento com o número de pseudoseptos, a análise de contrates ortogonais demonstrou que os esporos provenientes de tecidos verdes (folhas) foram estatisticamente superiores $(7,7)$ aos desenvolvidos sobre sementes $(7,2)$ e em meios de cultura $(5,7)$.

Também foi possível observar que os conídios desenvolvidos em tecidos verdes (folhas) apresentaram coloração marrom-oliva-clara e são ligeiramente curvados, ao passo que os esporos desenvolvidos em sementes ou meios de cultura mostraram-se mais escuros (marrom-oliva-escuros) e retos.

\section{Densidade de inóculo vs. intensidade de doença}

Decorridas 36 a $48 \mathrm{~h}$ da inoculação, as folhas de cevada, cultivar BR-2, passaram a evidenciar os primeiros sintomas: pequenas lesões cloróticas arredondadas, que evoluíram para pequenos pontos castanho-escuros no centro da lesão, rodeados por um extenso halo amarelo. Posteriormente, essas lesões se desenvolveram formando manchas alongadas ovaladas, de cor castanho-clara (no centro com um ponto escuro), com bordos difusos e halo amarelo proeminente ( $96 \mathrm{~h}$ após a inoculação) e mediam 0,5 a $3 \mathrm{~mm}$. Algumas manchas apresentaram, na parte central, uma área esbranquiçada rodeada por um halo castanho-escuro.

As relações entre a densidade de inóculo e a intensidade de doença, número de manchas/folha e severidade foram
TABELA 2 - Valores extremos de comprimento $\times$ largura $(\mathrm{em} \mu \mathrm{m})$ e número de pseudoseptos encontrados em conídios de Bipolaris sorokiniana desenvolvidos em diferentes substratos

\begin{tabular}{|c|c|c|c|}
\hline Substrato ${ }^{1}$ & $\begin{array}{c}\text { Valores } \\
\text { Máximos }\end{array}$ & $\begin{array}{c}\text { Valores } \\
\text { Mínimos }\end{array}$ & $\begin{array}{l}\text { Valores } \\
\text { Médios }\end{array}$ \\
\hline \multicolumn{4}{|l|}{ Meios } \\
\hline $\mathrm{BDA}^{2}$ & $100 \times 28$ & $29 \times 15(1)$ & $65,3 \times 22,8(4,8)$ \\
\hline$V-8^{2}$ & $88 \times 25$ & $25 \times 14(1)$ & $60,0 \times 21,0(5,3)$ \\
\hline $\mathrm{AA}^{2}$ & $95 \times 28 \quad(8)$ & $28 \times 15(1)$ & $65,9 \times 22,3(5,8)$ \\
\hline $\mathrm{ETA}^{2}$ & $91 \times 25 \quad(9)$ & $38 \times 14(2)$ & $70,1 \times 20,7(6,8)$ \\
\hline PF & $98 \times 30(10)$ & $35 \times 15(2)$ & $71,1 \times 22,5(5,9)$ \\
\hline MSR & $108 \times 33$ & $35 \times 18(1)$ & $76,6 \times 22,1(5,7)$ \\
\hline Média & $96,7 \times 28,2(8,7)$ & $31,7 \times 15,2(1,3)$ & $68,2 \times 21,9(5,7)$ \\
\hline \multicolumn{4}{|l|}{ Sementes } \\
\hline $\mathrm{SCv}$ & $100 \times 31(11)$ & $38 \times 18(1)$ & $73,9 \times 21,6(6,4)$ \\
\hline STg & $106 \times 23(11)$ & $43 \times 15(4)$ & $81,3 \times 19,3(7,7)$ \\
\hline $\mathrm{SCt}$ & $120 \times 28(12)$ & $33 \times 15(2)$ & $82,6 \times 20,8(7,4)$ \\
\hline STt & $108 \times 23(11)$ & $39 \times 15(4)$ & $75,6 \times 19,8(7,2)$ \\
\hline Média & $108,5 \times 26,2(11,2)$ & $38,2 \times 15,8(2,8)$ & $78,3 \times 20,4(7,2)$ \\
\hline \multicolumn{4}{|l|}{ Folhas } \\
\hline $\mathrm{FCV}$ & $125 \times 20(11)$ & $66 \times 15(4)$ & $94,7 \times 17,7(8,0)$ \\
\hline FTg & $123 \times 21(11)$ & $53 \times 15(4)$ & $92,8 \times 17,7(7,2)$ \\
\hline $\mathrm{FCt}$ & $125 \times 21(10)$ & $53 \times 15(3)$ & $95,7 \times 19,5(8,2)$ \\
\hline FTt & $128 \times 30(12)$ & $71 \times 15(5)$ & $88,5 \times 18,0(7,4)$ \\
\hline Média & $125,2 \times 23,0(11,0)$ & $60,7 \times 15,0(4,0)$ & $92,9 \times 18,2(7,7)$ \\
\hline
\end{tabular}

Média Geral 108,2 × 26,1 (10,1) 41,8 × 15,3 (2,5) $\quad 78,1 \times 20,4(6,7)$

\begin{tabular}{lrr}
\hline Contrastes ortogonais $^{3}$ & Erro & F \\
\hline Comprimento: & & \\
$\quad$ (Meios de cultura + Sementes) vs. Folhas & 0,155 & $361,83^{* *}$ \\
$\quad$ Meios de cultura vs. Sementes & 1,237 & $74,25^{* *}$ \\
$\quad \begin{array}{rr}\text { Largura: } \\
\quad \text { Meios de cultura + Sementes) vs. Folhas }\end{array}$ & 0,028 & $241,61^{* *}$ \\
$\quad$ Meios de cultura vs. Sementes & 0,043 & $48,87^{* *}$ \\
$\quad$ Número de pseudoseptos & & \\
$\quad$ (Meios de cultura + Sementes) vs. Folhas & 0,017 & $131,88^{* *}$ \\
$\quad$ Meios de cultura vs. Sementes & 0,027 & $120,71^{* *}$ \\
\hline
\end{tabular}

(1)Meios de cultura: batata-dextrosa-ágar (BDA), V-8-ágar (V-8), ágar-água (AA), extrato de tomate-ágar (ETA), papel-filtro (PF) e meio seletivo de Reis (MSR); Sementes: cevada (SCv), trigo (STg), centeio (SCt) e triticale (STt); Folhas: cevada (FCv), trigo (FTg), centeio (FCt) e triticale (FTt).

(2)Meios de cultura $+0,2 \mathrm{~g}$ de estreptomicina por litro de água.

(3)Análise de contraste ortogonal dos valores médios.

representadas por equações polinomiais quadráticas (Figura 1). Os dados demonstram um aumento crescente da intensidade da mancha marrom com o aumento da concentração de inóculo de B. sorokiniana atingindo o nível mais alto (ponto máximo) do número de manchas por folha e de severidade da doença $\%$ AFA, com $1,65 \times 10^{4}$ e 1,4 $\times 10^{4}$ conídios $/ \mathrm{ml}$, respectivamente, para, posteriormente, diminuir. Os pontos máximos corresponderam a 182 manchas/folha e $79 \%$ de severidade, valores equivalentes à média de duas folhas (folhas primárias emergidas após a plúmula). Em função dos resultados da Figura 1, é possível estimar que uma quantidade de 50 a 90 esporos seja necessária para produzir uma lesão.

\section{Substratos vs. morfologia de conídios}

Os gêneros e as espécies dos fungos imperfeitos são diferenciados através de características morfológicas como cor, 
Efeitos na fotossíntese e área foliar de cultivares de alface...

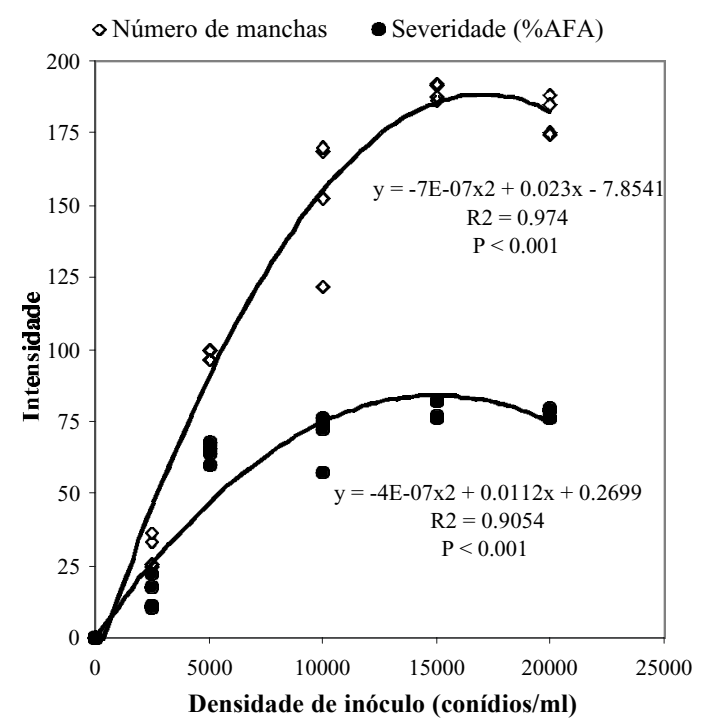

FIG. 1 - Efeito da densidade de inóculo de Bipolaris sorokiniana no número de lesões por folha e na severidade da mancha marrom em folhas de plântulas de cevada (Hordeum vulgare).

tamanho e septação de conídios e conidióforos, com considerações adicionais sobre a classe de hospedeiros (Kafi \& Tarr, 1966). Dentro do grupo dos fungos dematiáceos hyphomicetos como dos gêneros Bipolaris, Drechslera e Exserohilum, o tamanho dos conídios e o número de septos por conídios constituem-se num critério importante para a separação de espécies (Harding, 1975a). Porém, segundo esse autor, essas características podem ser afetadas pelo meio de cultura utilizado na produção dos esporos.

Os resultados obtidos neste trabalho (Tabela 1) corroboram o proposto por Harding (1975a), pois foram encontradas diferenças estatisticamente significativas $(\mathrm{P}<0,01)$ não só entre os quatorze substratos comparados, mas também quando eles foram agrupados em três tipos (Tabela 2). O agrupamento permitiu definir diferenças marcantes entre os conídios desenvolvidos em meios de cultura: $68,2 \times 21,9 \mu \mathrm{m}(5,7)$, como os mais curtos, largos e com menor septação; sementes: 78,3 $\times$ 20,4 $\mu \mathrm{m}$ (7,2), intermediários; e folhas verdes: 92,9 × 18,2 $\mu \mathrm{m}$ $(7,7)$, os mais longos, estreitos e com maior septação. Há referências de que diferenças no comprimento entre esporos produzidos sobre diferentes substratos, dos quais aqueles produzidos sobre folhas verdes de cevada foram 23 a $26 \%$ maiores aos produzidos no meio batata-dextrose-ágar e em espigas maduras de cevada (autoclavadas) (Lutrell, 1955). Por outro lado, o autor observou que temperaturas altas $\left(28{ }^{\circ} \mathrm{C}\right)$ induzem a formação de conídios curots, ao passo que temperaturas baixas $\left(14{ }^{\circ} \mathrm{C}\right)$ são responsáveis pela produção de conídios mais longos, variações que também foram reportadas por Ruppel (1974).

Segundo Elliott (1949), o comprimento e o número de septos dos conídios podem variar com a concentração de glicose adicionada ao meio de cultura, exercendo um marcado efeito sobre essas características. As fontes de carbono cons- tituem-se num fator que afeta as dimensões conidiais, porém menos significativo que o efeito da glicose (Kafi \& Tarr, 1966). Outros fatores, como o pH inicial do meio (Tarr \& Kafi, 1968; Harding, 1975a), as fontes de nitrogênio (Harding, 1975b) e a idade do meio de cultura (Ruppel, 1974), podem também afetar tais características.

Com relação aos valores extremos máximos, mínimos e médios (Tabela 2), as características conidiais estudadas, em geral, encontram-se dentro da descrição morfológica reportada por Ellis (1971) e Sivanesan (1987), que são: comprimento de 40-134 $\mu \mathrm{m}$ (geralmente 60-100), largura de 15-30 $\mu \mathrm{m}$ (geralmente 18-23) na parte mais larga do conídio e três a 12 (geralmente seis a dez) distoseptos ou pseudoseptos. Os poucos esporos encontrados com um só septo possivelmente são imaturos. Portanto, em razão dessas variações na morfologia dos conídios e de outras características culturais e fisiológicas, o fungo $B$. sorokiniana é considerado um patógeno que apresenta grande variabilidade, tanto morfológica quanto fisiológica (Tinline, 1988; Matsumura apud Oliveira et al., 1998). Por essa razão, em trabalhos de identificação ou reconhecimento do patógeno, devem-se padronizar as características conidiais em função do substrato onde o fungo foi cultivado ou recuperado para, assim, evitar possíveis erros na sua identificação. Sempre que possível, as dimensões padrões devem ser tomadas a partir de conídios formados sobre o substrato natural do hospedeiro por ser esse o substrato que ocorre na natureza.

\section{Densidade de inóculo vs. intensidade de doença}

As condições ambientais altamente favoráveis à mancha marrom $\left(25 \pm 1{ }^{\circ} \mathrm{C}\right.$ e 95 a $100 \%$ de UR por $\left.48 \mathrm{~h}\right)$ propiciaram a manifestação precoce dos sintomas da doença entre 36 a $48 \mathrm{~h}$ após a inoculação. Neste particular, tem sido relatado que o fungo $B$. sorokiniana requer entre 9 a $24 \mathrm{~h}$ de molhamento foliar para produzir infeção dos órgãos foliares, sendo o ótimo de 20 a 24 h (Couture \& Suton, 1978). Por outro lado, o desenvolvimento da doença é acelerado sob condições de alta umidade relativa e longos períodos de molhamento (Zillinsky, 1984), situação que vem corroborar a pronta manifestação e caracterização dos sintomas observados no presente experimento. Num período de dois a sete dias, os sintomas manifestaram-se em sua plenitude, ocasionando, em alguns casos (densidades de $1,5 \times 10^{4}$ e $2 \times 10^{4}$ conídios $\mathrm{ml}^{-1}$ ), necrose completa das folhas ( 95 a 100\% de severidade) por causa do elevado número de lesões por folha e do seu rápido desenvolvimento, coalescendo e ocasionando a morte prematura das mesmas.

Quanto à temperatura, é relatado que o ótimo para o desenvolvimento da doença oscila entre 22 e $30^{\circ} \mathrm{C}$, acelerandose com $24^{\circ} \mathrm{C}$ e produzindo maior número de lesões necróticas a $28^{\circ} \mathrm{C}$ (Clark \& Dickson, 1957; Luz \& Bergstrom, 1986).

A determinação da concentração ótima de inóculo, assim como do seu potencial, é necessária quando se objetiva obter dados reproduzíveis e, portanto, padronizados, assim como para elucidar aspectos biológicos do patógeno-alvo do estudo ou epidemiológicos da doença (Fernandes et al., 1991). Em função da tendência da curva quadrática (Figura 1), verificou- 


\section{J.T. Barba et al.}

se um incremento significativo da intensidade da doença até atingir 1,65 × $10^{4}$ (número de manchas por folha) e $1,4 \times 10^{4}$ conídios/ml (severidade da doença), quando, então, tendeu a diminuir. Isso pode ser atribuído ao fato de que altas densidades de inóculo podem produzir um efeito antagônico na germinação dos esporos e/ou vários esporos podem participar de uma única infecção. Segundo esse último, a severidade de doenças pode aumentar proporcionalmente com a concentração de esporos do patógeno até uma determinada concentração, acima da qual, dependendo do patossistema, pode ocorrer uma redução, causada, provavelmente, pela autoinibição da germinação dos esporos, assim como pela existência de um número limitado de sítios de infecção Não se encontrou, na literatura pesquisada, qualquer informação específica sobre esses fenômenos para B. sorokiniana, sendo, portanto, necessária a confirmação desta hipótese. Quanto à quantidade de esporos necessários para produzir uma lesão (50 a 90 conídios), o desconhecimento da viabilidade dos mesmos (\% germinação) não permite precisar com exatidão o número ótimo.

Por outro lado, em fitomelhoramento, a definição da densidade ótima e do potencial do inóculo para uso em trabalhos de seleção é de vital importância. Como indicam Carvalho et al. (1981), quando se trata da verificação de níveis de resistência ou seleção de plantas resistentes à enfermidade, altas ou baixas concentrações poderiam comprometer a reação do material testado. Nesse sentido, em trabalhos rotineiros de melhoramento de cevada desenvolvidos em Minnesota, nos Estados Unidos, concentrações de esporos que oscilam entre $5 \times 10^{4}$ e $1 \times 10^{5}$ são utilizadas (Wilcoxson et al., 1990). Essas concentrações superam em 300 a $600 \%$ as determinadas neste trabalho, o que, conseqüentemente, pode determinar a eliminação de materiais em programas de melhoramento e a necessidade de muita mão-de-obra na multiplicação de inóculo, especialmente quando se trata de programas de melhoramento em grande escala.

\section{REFERÊNCIAS BIBLIOGRÁFICAS}

CARVAlHO, L.P., CARVALHO, J.M.F.C., LIMA, E.F. \& CAVALCANTE, F.B. Influência da concentração de esporos da patogenicidade de Colletotrichum gossypii South var. cephalosporioides A.S. Costa e avaliação da resistência de cultivares e linhagens de algodoeiro herbáceo à ramulose. Fitopatologia Brasileira 6:395-402. 1981.

CLARK, R.V. \& DICKSON, J.G. The relation of temperature on disease development by Helminthosporium sativum on barley. Phytopathology 47:6. 1957

COUTURE, L. \& SUTTON, J.C. Relation of weather variables and host factors to incidence of airborne spores of Bipolaris sorokiniana. Canadian Journal of Botany 56:2162-2170. 1978.
ELLIOTT, E.S. The effect of the sugar concentration on conidial size of some species de Helminthosporium. Phytopathology 39:953-958. 1949.

ELLIS, M.B. Dematiaceous Hyphomycetes. Kew, Surrey, England. Commonwealth Mycological Institute (CAB). 1971.

FAO. Manual para patólogos vegetales. $2^{\text {da }}$ ed. Santiago de Chile. 1985. FERNANDES, C.D., DEL PELOSO, M.C., MAFFIA, L.A., DO VALLE, F.X.R. \& ZAMBOLIM, L. Influência da concentração de inóculo de Cercospora coffeicola e do período de molhamento foliar na intensidade da cercosporiose do cafeeiro. Fitopatologia Brasileira 16:3943. 1991.

HARDING, H. Effect of $\mathrm{pH}$ and sucrose concentration on conidium size and septation in four Bipolaris species. Canadian Journal of Botany 53:1457-1464. 1975a.

HARDING, H. Effect of d-amino acids on conidium size and numbers of pseudosepta por conidium in isolates of Bipolaris sorokiniana. Canadian Journal of Botany 53:600-603. 1975b.

KAFI, A. \& TARR, S.A.J. Growth, sporulation and conidial characteristics of five graminicolous species of Helminthosporium: I. Effect of nutrients. Transactions British Mycological Society 49:327337. 1966.

LUTTRELL, E.S. A taxonomic revision of Helminthosporium sativum and related species. American Journal of Botany 42:47-68. 1955.

LUZ, W.C. da \& BERGSTROM, G.C. Temperature-sensitive development of spot blotch in spring wheat cultivars differing in resistance. Fitopatologia Brasileira 11:197-204. 1986.

OLIVEIRA, A.M.R., MATSUMURA, A.T.S., PRESTES, A.M., MATOS, G.S. \& VAN DER SAND, S.T. Variabilidade patogênica e morfológica em isolados de Bipolaris sorokiniana. Fitopatologia Brasileira 23:349-353. 1998.

REIS, E.M. Selective medium for isolating Cochliobolus sativus from soil. Plant Disease 67:68-70. 1983.

RUPPEL, E.G. Factors affecting conidial dimensions of a Drechslera species. Mycologia 66:803-807. 1974.

SIVANESAN, A. Graminicolous species of Bipolaris, Curvularia, Drechslera, Exserohilum and their teleomorphs. Wallingford, UK. CAB International Mycological Institute. 1987.

STEFFENSON, B. Spot blotch. In: Mathre, D.E. (Ed.). Compendium of barley diseases. St. Paul, Minnesota. APS Press. 1997. pp.35-36.

TARR, S.A.J. \& KAFI, A. Growth, sporulation and conidial characteristics of five graminicolous species of Helminthosporium: II. Effect of nitrogen and $\mathrm{pH}$. Transactions British Mycological Society 51:771-777. 1968 .

TINLINE, R.D. Cochliobolus sativus, a pathogen of wide host range. In: Ingram, D.S. \& Williams, P.H. (Ed.) Advances in Plant Pathology. Genetics of Plant Pathogenic Fungi. v.6. California. Academic Press. 1988. pp.113-122.

ZILLINSKY, F.J. Guía para la identificación de enfermedades en cereales de grano pequeño. CIMMYT. El Batán, México. 1984. 